\title{
VARIATION ON A THEME BY PARKINSON OR SOME PROPOSALS FOR THE UNIFORM COMMERCIAL CODE AND THE CHECKLESS SOCIETY*
}

\author{
GERALD T. DUNNE†
}

WE have Professor Parkinson's word for it that the physical externals of a system may never be more impressive than when the curtain is about to fall. ${ }^{1}$ Thus, he tenders St. Peter's in Rome as a monument both to the end of the Renaissance papacy and the beginning of the Protestant Reformation, and along much the same line, he suggests that the proximity of the completion of Versailles and the outbreak of the French Revolution was not an ironic coincidence but, on the contrary, a closely and causally related sequence. Presumably, his admonition can apply to the mundane as well as the spectacular and to ways of doing things as well as organizations. If it can and if we seek an incipient example in the workaday world, we could well take a look at the present form of the American collections-payments mechanism.

Certainly, if an assumption of indispensability, universality of acceptance, magnitude of product, or impressiveness of artifact may be symptoms of pride going before a fall, then there is no lack of possible omens of crisis in that mechanism and, more specifically, in the check, its symbol and instrument. To be sure, and Professor Parkinson to the contrary, these characteristics can signify golden age as well as Indian summer; irrespective of their import, however, it is virtually impossible not to be aware of their existence, for these characteristicsor at least some of them-are incessantly proclaimed by every form of advertising medium. Primarily, these assertions stress safety and convenience, characteristics of the check which probably go back to the clay tablet prototypes in Babylon. But emphasis is also laid on

* The opinions expressed are personal to the author, who wishes to acknowledge indebtedness for the critical commentary of colleagues in the Federal Reserve System, particularly John J. Clarke, Vice President and General Counsel of the Federal Reserve Bank of New York, and John R. Farrell, Director, Division of Bank Opcrations of the Board of Governors. Needless to say, their kindness involves no responsibility for the vicws herein.

† General Counsel, Federal Reserve Bank of St. Louis.

1. Parkinson, Parkinson's Law 6I-63 (1957). 
relatively modern aspects which are particularly congenial to the temper of the times-widespread availability through a variety of service charge arrangements; prestige of name-and-address imprintation; choice of color, size and binding; value as business record and legal receipt and so on. In fact, these latter characteristics seem so exceptionally enmeshed with modern values, habits and attitudes that it may well be argued that they constitute far more a guaranty of permanency than a portent of decline and fall.

These features, old and new, have necessarily contributed to the ever-increasing use of the check in the economic environment which has characterized the United States since the end of World War II. But prosperity and population, taken together, constitute the major factors in this seemingly open-ended expansion. Indeed, the development symbolized in the rise of the two-car family can as easily be depicted as the rise of the two-account one. (". . . [P] ut two hundred in the housekeeping account," says one of Marquand's heroines.) ${ }^{2}$ Or perhaps, the two-account family is itself fast becoming a casualty of the evolving financial precocity of a child-centered culture, for the most casual sampling of high school juniors and seniors will show a substantial portion of them as checking account holders. Thus, the recent CBS television program, "Sixteen in Webster Groves" stated that 78 per cent of the sixteen year olds studied had their own checking accounts.

In fact, every development in modern American life increasingly expands the vast and deep flood of paper which has been swirling back and forth across the land. New family formation means more streams of checks from more accounts, and so does family un-formation with its support and alimony payments. The ever-rising tide of installment credit, substituting many payments for one, produces another broad tributary. So does the shift from the farm to the city and the flight from the city to the suburbs. So does interregional migration. So does every decision of an employer to shift from a cash to a check payroll. So does every union request for a biweekly, rather than a semimonthly, pay period. So does every increase in gross national product. And so on and so on with every element in the ongoing complexity and variety of American life reflecting its character and adding its burden upon the national collections-payments mechanism. Accordingly, the number of checks has soared upward in astronomical progression. The estimates-for nobody really knows-suggest a rise from 3.5 billion

2. Marquand, Point of No Return 6 (1949). 
in 1939 to 8 billion in 1952 , to 15.5 billion today, to 20 billion by $1970 .^{3}$

Of necessity, this proliferation of paper has left its mark on the collections-payments mechanism. Legal formularies have been cut almost to the bone. Specialized carriage and transport have been increased. New clearing and collection arrangements have been encouraged. Innovational (or, sometimes more accurately, renovational) techniques, such as the nonreturn of paid checks, have been explored. But the principal response has come in a fantastic surge of productivity made possible by new check handling machinery. And this particular development was a matter of absolute compulsion, for as one commentator put it, without automation to handle the increasing amount of checks, by 1970 American bankers "would face a clear-cut choice: hire every American woman between 21 and 45 or be inundated in a rising tide of paper." 4

Nonetheless, when all is said, all the developments so far have done is to accept the tidal wave as a fact and attempt to provide channels for its direction and control. That the crest of the tidal wave will go higher in the current set of the matter, that this result carries with it further undesirable consequences, and that this portending state of affairs cannot be touched by further purely mechanical improvements has been increasingly asserted. And the nature of this state of affairs is to suggest that the headwaters, not the crest of the flood, is the place where the next moves must be made, and these moves will probably go to the character rather than the consequences of the payments instrument. And these must start with the premise that for all its advantages, the check, as we know it, is an inherently inefficient payments instrument. At its routine best, it makes a double trip going from drawer to payee and back again. At its dishonored worst, it makes but part of that trip, only to stop short of completion and retrace its partial original route, perhaps once, perhaps several times. And whether it makes the complete or partial trip, it does so in stages with a variety of intermediate handlings.

It is this "back-and-forth" syndrome which will provide, which indeed has already provided, stimulus for reform. And well it might,

3. STUDY of THE Check CoLrection System, Report of Joint Committce on Chick Collection System to The American Bankers Association, Association of Rescrve City Bankers, Conference of Presidents of Federal Reserve Banks 1 (1954). [Hereinafter citcd as Study.] Watson, Man and Machines-The Dynamic Alliance, American Bankers Association, Proceedincs, National automation Conference 9, 10 (1965). [Hercinafter citcd as Proceedings.] Clarke, Legal Aspects, Procezdings 449, 450.

4. Watson, ProceEdincs 10. 
for there is nothing inherent in the nature of a check which demands a complete round trip, that is, that the drawee bank return the paid and cancelled instrument to its customer. Fifty years ago, American banks did not do so, and some European banks do not do so today. In fact, certain Levantine institutions would regard it as madness to surrender to a customer the very evidence of the basis for having charged his account in the first place. However, in American banking, the introduction of the posting machine a half-century back brought with it the practice of returning checks with skeletonized information to enable the depositor to verify his account.

Now, proving perhaps that there is nothing new under the sun, a significant shift in the tide has come in efforts of at least one bank to restore the status quo ante and to permanently retain paid checks subject to inspection on a customer's request. ${ }^{5}$ This is, of course, a constructive, meritorious reform for bank and customer alike by eliminating handling, wrapping and mailing charges as items from the pricecost squeeze. Nevertheless, there are countervailing costs in terms of customer education, and they must come high. And a still more basic limitation is the fact that this reform does not touch the basic defects of the check as a payment mechanism. Rather, it deals only with the last (and in a payment sense, irrelevant) stage of the check's journey and accordingly touches only a small part of the paper swirl involved in the 60 million checks which may be written on any given day in 1966. Nonetheless, it is an imaginative and progressive step, warranting legal fortification and amplification. Such might be had by amplification of Article Four of the Uniform Commercial Code so as to explicitly authorize (1) the destruction of paid checks by a payor bank and (2) the complete and ready use of a duly authenticated photocopy in lieu of a destroyed original. ${ }^{\circ}$

Using the analysis of a 1954 study, one out of five of these checks will be deposited in the bank on which drawn. As to these "on us" checks, the payment mechanism will be efficient enough. One account will be charged and another credited in an integrated and terminal transaction. Or should the account of the drawer be unable to support the charge, the fact is readily ascertained and given immediate accounting effect. Indeed, were all checks drawn on one bank with one office, much (but by no means all) of the current difficulties would be obviated. But they are not and cannot be, and, hence, analysis of problems must begin with the fact that about 80 per cent of checks are

5. Livingston, The Chech's Future, Procerdincs 142.

6. See proposed Uniform Commercial Code Section $4-408$ in Appendis, infrc. 
deposited in banks on which they are not drawn. Of these about one third will be collected through a local clearing arrangement and the remaining two thirds by delivery to a correspondent and/or a Federal Reserve Bank. With respect to the overall pattern resulting from this complex of circumstances, the 1954 study produced some other interesting and presumably still valid statistics:

1. That the average check takes $2-1 / 3$ business days to collect;

2. That it goes through $2-1 / 3$ banks in the process of collection;

3. That 40 per cent of all checks are drawn on 207 banks;

4. That two thirds of one per cent of all checks are returned unpaid, over half NSF and a fifth for endorsements;

5. That 64 per cent of checks returned unpaid are for under $\$ 100 .^{7}$

Important enough a decade ago, the foregoing matters take on fresh and meaningful significance in today's world. The annual cost of this system is estimated at 3.3 billion dollars, ${ }^{8}$ and the figure has no way to go but up, at least in the short run. Prophecy is hazardous business, of course, and prediction on a subject as vast, complex and diffuse as the check collection system is especially so. Nonetheless, several generalized observations may be warranted. The first is that further economies of scale cannot be presumed; on the contrary, prudence would estimate that further increases in check volume will produce increases in costs. While the hope may be ventured that the two increases run in some rough tandem, it may well be that the very nature of the system will exact a disproportionate toll as an ever-growing load is placed upon it by both the "round trip" aspect of check payment already noted and the fact that there is superimposed upon this horizontal circularity a vertical pattern of motion produced by the constant assembly, dispersal and reassembly of checks in transitu. The obvious and growing disadvantages of this "stop-shuffle-and-go" paper merry-go-round in an age of direct long-distance dialing and other communication marvels strongly suggest that it is only a matter of time until the collectionspayments mechanism undergoes a basic reform which produces the speed, directness and certainty which, on one hand, technology affords and, on the other, modern financial conditions demand.

How can the mountains be laid low, circuity give way to directness, slowness to speed and imprecision to certitude? Quite possibly, these results will come about in a small but immensely pivotal change where-

7. STUdY 1-2.

8. Mitchell, The Impact of Automation on Bank Structure and Function, American Banker, Dec. 30, 1965, p. 4. [Hereinafter cited as Mitchell.] 
in the payor bank becomes, so to speak, the direct rather than the indirect object of its depositor's order. In other words, the depositor would direct his order in the first instance, not to his payee, but to his bank, who would then be responsible to carry it out and get the funds to the designated payee. And in the execution of the order, there would not be transmitted a piece of paper but an electronic impulse with an attendant increase in dispatch and efficiency. In short, there would be a shift from a "check" system to a "transfer" system, which would, in effect, bring to interbank transactions much the basic efficiency which now attends the intrabank ones of "on us" checks.

At its theoretical optimum, such a system could dispense with paper entirely. Thus, there already exists the Bell Touch-Tone System where combining a pre-punched card with the existing dial telephone apparatus makes possible the instant transmission and handling of billing and payment orders. ${ }^{9}$ The possibilities of this system are immense, especially when considered in a context of credit card standardization and a process of "instant" authentication of such a uniform card-say, by fingerprint imprintation at each using. Even more fantastic is the possibility of initiating the transfer order by voice alone; according to experts this procedure would be perfectly practical and safe (for voices are as distinctive as fingerprints). Indeed, as these lines are written, the New York Times of April 12, 1966, carries the story of the first use of a "voice print" in a criminal trial.

Yet, from the wheel on, every improvement in accustomed ways of doing things must take account of that resistance to change in the familiar whereby men seem sometimes more willing to yield their lives than to yield their habits. And, unquestionably, there is a point where an innovation does such violence to habituation that it will simply not be accepted whatever its theoretical merit. Thus, shorthand has not yet replaced (and probably never will) ordinary script as the usual mode of writing. Neither will Christian or family names be surrendered for Social Security numbers. In fact, the resistance to abolition of localityoriented telephone exchange names for three-digit prefixes suggests that the technological revolution with its overtones of depersonalization and anonymity excites in an especially inflammatory way the pre-existing disposition to retain the old and to resist the revolutionary. Thus, particularly resistant to the potential miracle of voice-initiated payment is the habituation, or perhaps we should more properly call it the deepseated instinct, to record and retain transactions in tangible, manipula-

9. See Next Stop in Banking: Pay Bills by Phone, Business Wcek. Nov. 13, 1965, p. 82. 
tive symbols. But whether it is habit or instinct, there must be taken into account the ingraining this propensity has been given by the longtime advertising campaign of banks on the virtues of receiving and retaining cancelled checks.

To be sure, there is some countervailing force at work in another form of advertising wherein some prestigious public figure proclaims, "I never carry more than $\$ —$ in cash." Currently, this attitude is directed towards checks, but its transferability to credit card systems is apparent. However, the net of these related forces seems very strongly on the side of continuity rather than change, and, hence, any "transfer" system which evolves will probably contain a residuum of technically unnecessary but psychologically indispensable paper. Thus, the initiating "transfer order" may well be paper, probably of uniform size and containing certain pre-coded information. Much as he now writes a check (including a stub entry for his own records), a depositor can inscribe such a transfer order-including the payee's banking number -and send it to his own bank for processing and execution. Upon receipt there, the transaction is transformed electronically into a singleshot, one-way, speedy transfer of credit between bank accounts. Some "output" for payee notification is necessary, of course. Again this doubtless will be paper-perhaps, a computer "print out" of each credit entry or possibly a daily detailed transcript of account. These input and output vestiges, however, only underscore the immense benefits flowing from the elimination of paper otherwise-" "no check sorting or resorting, no shipment of checks from bank to bank or bank to customer, no storage requirements for checks, no kited checks, no endorsements, no NSF checks, no float and a minimum of manual handling." 10 And these direct benefits would fan out to collateral areas. Corporate comptrollers and treasurers would no longer be concerned with outstanding checks, reconcilements, reversed entries by reason of unpaid instruments, or waiting for deposits to become available. Lawyers, particularly bank counsel, might also find the results largely to the good. "(T)here would disappear the action for slander of credit based on wrongful dishonor. There would be no need to worry about forged endorsements or raised checks."11

And this would be but the beginning. For it would be a short and simple step for billings of almost every nature-business accounts, utilities, department stores, etc.-to submit these statements in the form of

\footnotetext{
10. Mitchell, p. 4.

11. Clarke, Legal Problems Are Not Insurmountable, American Banker, Dec. 1, 1965, P. $2 A$.
} 
a transfer order which the customer can validate and send on to his bank. Or perhaps, such billings can be in the form of encoded decals which the customer can in turn attach to his pre-numbered and preencoded forms. Moreover, this shift from a check system to a transfer system has an enormous repository of experience to draw upon, for this is the "giro" system long conducted in many other countries. But we need not look so far away; there already exists an American prototype of a mechanism wherein payments are initiated by instructions directly to the paying bank rather than via the payee and are carried out through the transmission of an electric impulse rather than a piece of paper. For many years, the Federal Reserve wire transfer procedure has operated on this basis. The heart of this system is the Interdistrict Settlement Fund and a switching center. Its components are the six thousand-odd reserve and clearing balances on the books of the twelve Federal Reserve Banks.

This system is not only available for transactions between member banks for their own account. It may and, in fact, is used for wire transfers of funds where the member banks merely serve as the conduits for others. ${ }^{12}$ Realism, however, demands recognition of immense problems involved in transforming the wire transfer system to a "retail" basis even though the apparatus, the techniques and the experience already exist. For one thing, only a minority of the nation's banks have accounts on the books of the Fed, although those that do, taken as a whole, not only handle the bulk of checks, but also hold balances from nonmember banks. Hence, while most of the germinal innovations of a transfer system "are now in being or are about to be placed in operation,"13 a host of relevant and complicating factors will extend the time of their flowering. One is the necessity of minimizing the foul-up potential in a system based on manual inputs. (Here one is reminded of the New Yorker cartoon of the children's game wherein the participants dial ten numbers at random, and the winner is the child reaching the most distant city.) Still another is historical-the legacy of past efforts to bring reforming improvements to the collections-payments mechanism. ${ }^{14}$

But even more certain to extend and complicate the transition process is the question of who will pay for what. It is a safe prediction that a transfer system will be expensive. It is hazardous to suggest that its

12. See, e.g., Some Short-Cuts in the Money Transfer Routine, Burrotchis Clearunc House, Oct. 1945, p. 41.

13. Mitchell, p. 10.

14. See Wyatt, The Par Clearance Controversy, 30 VA. L. REv. 361 (1944). 
expense will be borne through the present complex and diffuse process, whereby some costs are paid by the Federal Reserve, some by drawers via service charges, some by payees via exchange charges, and the bulk by commercial banks in their quest for balances. ${ }^{15}$ For the present system is the end product of an immensely complex evolution and takes much of its configuration from the check itself. Hence, the safer assumption is that the present cost distribution process cannot be carried over pari passu from one system to the other.

Moreover, the formulary of cost distribution will be itself the consequence of the kind of transfer system which actually emerges. Thus, a national computer system following the COMSAT model doubtless will produce one pattern, and a decentralized complex of many local computer systems will produce another. ${ }^{16}$

Hand in hand with these complex and formidable issues are some legal questions. Possibly some a priori legal restructuring might be desirable. Compared to the practical problems, however, the legal problems seem relatively simple. For what is basically needed in a transfer system is "a clear and comprehensive agreement ... to be made between depositor and depositary ... [but which] would bring about no fundamental change in the bank depositor relationship ...."17 Perhaps the framework for such agreement could be provided in the form of a new and additional chapter on transfer payments in the existing Article Four of the Uniform Commercial Code, which might in turn be relabeled "Bank Deposits, Collections and Transfers." To re-emphasize: there is no necessity at this time to amplify the Code in the foregoing particular, and to do so might invite all the hazards which premature codification can involve. On the other hand, the existing design of Article Four is, conceptually and verbally, hospitable to incorporation of a transfer system, and, perhaps, this is one of the cases in which law might lead rather than follow the world of affairs by providing not only an initial foundation for relationships, responsibility and vocabulary, but also an infrastructure capable of supporting development as experience unfolds. Here the provision of Section 4-103(3) of the Code, which gives the Federal Reserve regulations and operating letters the effect of agreement by all interested parties, assumes particular significance, for it affords the legal base for a molecular development of law which takes account of both national needs and local requirements. Possible additions (including some parallel additions to Article Three) and a commentary thereon are set out in the attached Appendix.

\footnotetext{
15. Mitchell, p. 4.

16. Cf. Mitchell, pp. 4, 10; Clarke, Procredincs 455.

17. Clarke, supra note 11 , at $2 \mathrm{~A}$.
} 
In addition to these incentives, another motive for undertaking such action lies in a particular advantage, resulting from giving the banking industry an advance legal matrix for transfer operations. Banking is conservative and prefers its law settled, explicit and definitive. Its conservatism, here and elsewhere, grows out of the very necessity of the case. However valuable an itch for change and a taste for experimentation may be elsewhere, they should be minimal in organizations handling other people's money. As Walter Bagehot said almost a century ago, adventure may be the life of commerce, but caution is the life of banking.

Moreover, and in addition to this basic institutional character, it should be remembered that banking inverts the usual business process by being a salesman in getting its materials (deposits) and a prospect in disposing of its products (loans). The consequences of this sequence can be exemplified in one simple fact of life, and it need not be labored: the salesman takes the customer to lunch, not vice versa. More specifically, in their loan and investment operation, banks deal from a position of strength which is quite different from that obtaining in their deposit relationships. On the contrary, the type of a deposit account which is opened and the methods of charges against it-whether check or transfer or both-will be determined by what the customer wants and not what the bank thinks he should have. However, a revision of the Code in the foregoing particular, while concededly neither critical nor decisive, would nonetheless be an element in the process of producing an environment in which banks will be more receptive to presenting, and their customers to receiving, proposals for new ways of making payments.

Needless to say, however, banks are not completely without initiative in shifting a deposit relationship from one basis to the other. In fact, the shift has begun already and begun at bank suggestion in automated payroll plans. Under these arrangements, an employer furnishes a bank with the names and amounts, and employees are "paid" with a deposit credit. Use of the credit is up to the employee. He can draw on it as a regular bank account. Or if he wishes, he can write a single check to his own order for the entire amount and deposit it in his regular bank.

This "salary by credit" has been given two strong boosts. One is a court decision, finding that such an arrangement is not an illegal tie-in in restraint of trade. ${ }^{18}$ The other is a recently enacted statute, ${ }^{10}$ permitting government employees (and others) to be so paid, and the Treasury

18. Bank of Utah v. Commercial Security Bank, 1965 Trade Cas 7 71,540 (D.C. Utah).

19. Pub. L. No. 145, 89th Cong., 1st Sess. (Aug. 28, 1965), 79 Stat. 582. 
regulations thereunder have been published and adopted. Perhaps, the checkless payday, both governmental and business, would be the opening wedge of the new order, for it offers formidable advantages to all. For the banks, its merit is obvious. For employers, in addition to its savings in accounting and administrative costs, it eliminates or at least minimizes the unauthorized but widespread practice of "a few minutes" departure to cash or deposit checks during working hours. For employees, it saves not only a trip to the bank, but even the effort of banking by mail and provides him with instant bank credit the day his salary is due. And the reduction of payday traffic in bank lobbies-sometimes reminiscent of the runs of the '20's-should be welcomed by everyone.

On the other hand, it must be recognized that the growing use of such a salary payments method does not necessarily mean net gain in the short run. On the contrary, such a development may actually increase the paper torrent by bringing home in a particularly impressive way the advantages of checking accounts to people who do not have them. Indeed, here and elsewhere, the perverse consequence of steps looking to improvements in the future may well be additional burdens in the present. And, doubtless, the first substantial installation of a transfer system will produce, in addition to all the foregoing problems of technology, configuration and cost allocation, the additional difficulties of two overlapping payments mechanisms, existing side by side, with one in decline and the other growing in a trial-and-error process.

And if such intermediate developments suggest that the night may grow darker before the dawn-and the new day may be twenty-five to thirty years in coming ${ }^{20}$-optimism may be further tempered by the apprehension that the new dispensation will not settle every trouble spot in the transfer-payment mechanism. On the contrary, there is no reason to assume that the ritualized, conjugal dialogue which presently attends certain aspects of a check system will be materially different under a transfer one. For to return to Marquand:

"And don't forget ... . to put two hundred in the housekeeping account. It's down to twenty dollars and I'm going to draw on it today."

"What, again?"

"Yes, again and again and again."21

20. See Martinburger, Decline and Fall of the Check, The Bankers Magazinc, Summer, 1965 , p. 84.

21. Marquand, op. cit. supra, note 1. 


\section{APPENDIX}

\section{Preliminary Note}

Revision of the Uniform Commercial Code to accommodate a giro or transfer system involves at least two preliminary problems, one of nomenclature and one of structure. The first is what to call the direction or order involved. The other is how to "work in" the substantive amendments into Article Four.

On the first point, there already exists banking terminology. Unhappily, however, it involves some ambiguity. The phrase "transfer of funds" can be used in two senses. One is the order which a bank receives to make such a transfer via interbank transmission; the other concerns its action in carrying out such order. Under this circumstance, it would seem the better course to avoid the existing lexicon and resort instead to a coined term. "Bank transfer order" is the one suggested. Concededly long-handled, it does have the virtue of being precise and descriptive. Another possibility is "giro," which is shorter and also draws on a certain technical signification. However, it is rejected as too strange sounding.

With respect to engrafting the transfer system into Article Four, two opposite courses are possible. One is to integrate the transfer system into the existing text. The other is to add a new and virtually self-contained Part 6 to the Article. The first is an immensely tempting path, for a transfer system, conceptually and operationally, has much in common with the remittance "backtrack" of funds which a payor bank makes to a depositary bank in discharging a check. Hence, it is theoretically possible to "stitch" one process into the other by amplifying certain provisions and definitions, and this can be somewhat readily done in some instances, e.g., "depositary bank" and "payor bank." Adding to the temptation is the counterpart consideration that a selfcontained part involves some unnecessary, and indeed undesirable, overlapping and duplication. Nonetheless, this is what has been done in the proposed Part 6, "Bank Transfers," which is proposed for addition to Article Four. It has been done for two reasons. The first is that the "stitching" process would force certain definitions and provisions to be expanded well past the point of obscurity. The second is that the novelty of the subject suggests it be written on a tabula rasa.

As part of the process of change, three amendments to Article Three are also proposed. Two are intended to obviate the possibility of negotiability becoming involved in transfers of funds by nipping in the 
bud any legal encouragement to use bank transfer orders as checks.

New material is underlined save in those instances where it is indicated that an entirely new section is being proposed.

In addition to the amendments suggested, consideration might also be given to changing the word "transfer" and its derivatives where these appear in connection with collecting banks to "transmit," etc. (E.g., Sections 4-202(1)(e), 4-203 and 4-207(2)).

ARTICLE 3

Commercial Paper

Part 1

"Section 3-102. Definitions and Index of Definitions.

(3) The following definitions in other Articles apply to this article: ....

'Bank transfer order.' Section 4-601. ...."

"Section 3-103. Limitations on Scope of Article.

(1) This Article does not apply to money, documents of title, bank transfer orders or investment securities. ...."

"Section 3-805. Instruments Not Payable to Order or to Bearer.

This Article applies to any instrument whose terms do not preclude transfer and which is otherwise negotiable within this Article but which is not payable to order or to bearer, except that there can be no holder in due course of such an instrument. This Section has no application to a bank transfer order."

ARTICLE 4

Bank Deposits, Transfers and Collections

\section{Part I}

General Provisions and Definitions

"Section 4-101. Short Title.

This Article shall be known and may be cited as Uniform Commercial Code-Bank Deposits, Transfers and Collections." 
"Section 4-104. Definitions and Index of Definitions.

(2) Other definitions applying to this Article and the sections in which they appear are:

\section{'Bank transfer order' \\ 'Transferor' \\ 'Transferee' \\ 'Transferor bank' \\ 'Transferee bank'}

Section 4-601.

Section 4-601.

Section 4-601.

Section 4-601.

Section 4-601."

NEW MATERIAL

ARTICLE 4

Part 4

Relationship Between Payor Bank and Its Customer

Section 4-408. Destruction of Paid Items.

(1) A payor bank is authorized to destroy any item upon which it has made final settlement, provided it first makes a photocopy of the item and all endorsements thereon.

(2) Any such copy accompanied by a certificate of destruction under seal of the bank shall be admitted in all proceedings without further authentication or attestation to the same extent as the original check.

\section{Part 6}

Transfers of Bank Credit

Section 4-601. Bank Transfer Order; Transferee Bank; Transferee.

In this Article unless the context otherwise requires:

(1) "Bank transfer order" means an item issued by a transferor directly to a transferee bank directing the payment of a sum certain to a designated transferee bank for the credit of an indicated transferee;

(2) "Transferor" means any person from whom a bank has agreed to take bank transfer orders and includes another bank;

(3) "Transferee" is the person designated to receive ultimate credit for the amount of a bank transter order; 
(4) "Transferor bank" means any bank receiving a bank transfer order from a transferor;

(5) "Transferee bank" means a bank on whose books the account of the transferee is carried.

Section 4-602. Methods of Transfer and Payment.

(I) If the transferor bank and transferee bank are the same, a bank transfer order is effected by being charged to the account of the transferor and credited to the account of the transferee.

(2) Where the transferor bank is not the transferee bank, it may effect a bank transfer order by charging the account of the transferor and directing a bank with which it has an account to charge such balance with the amount of the order and pass credit to or for the account of the transferee. If the bank receiving such order is not the transferee bank, it may pass such credit by a bank transfer order directed to the transferee bank or a bank holding an account of the transferee bank. A telegraphic or electronic transmission of any such direction between banks is an "item" within the definition of Section 4-104(g).

(3) A transferor bank must effect a bank transfer order by a reasonably prompt method, taking into consideration any relevant instructions, the nature of the transfer, the number of such orders on hand, the cost of transfer involved and the method generally used by it or others to effect such transfers.

Section 4-603. Responsibility for Transfer; When Action is Timely.

(1) A transferor bank must use ordinary care in

(a) effecting a bank transfer order;

(b) giving notice to the transferor of any delay in or failure of transfer within a reasonable time thereof.

(2) A transferor bank taking proper action before its midnight deadline following a receipt of a bank transfer order acts seasonably; taking proper action within a reasonably longer time may be seasonable, but the bank has the burden of so establishing.

(3) Subject to subsection (1)(a), a transferor bank is not liable for the insolvency, neglect, misconduct, mistake or default of a transferee bank.

Section 4-604. Delays.

Delay by a transferor bank beyond time limits prescribed or permitted by this Act or by instructions is excused if caused by interrup- 
tion of communication facilities, suspension of payments by another bank, war, or emergency conditions beyond the control of the bank, provided it exercises such diligence as the circumstances require.

Section 4605. Finality of Transfer.

A transfer is considered accomplished when the amount thereof has been posted to the account of the transferor or other person to be charged therewith. 


\section{THE YALE LAW JOURNAL}

\begin{tabular}{lll}
\hline VOLUME 75 & APRIL 1966 & NUMBER 5 \\
\hline
\end{tabular}

Peter L. Zimkoth

Editor-in-Chief

\author{
E. EDWARD BRUCE \\ CAMERon F. MAcRaE, III \\ BENNO C. SCHMIDT, JR. \\ LARRY G. SIMON \\ Note \& Comment \\ Editors
}

BRUCE ACKERMAN
JOHN R. ADLER
LEONARD BECKER
STEPHEN BOMISE
CHARLES N. BURGER
LEONARD CHAZEN
THOMAS CHILDERS
BARRY CRAIG
WALTER E. DELIINGER, III
ARDEN DOSS, JR.
W. LEE H. DUNHAM
VIRGINIA B. EISENSTEIN
JOHN EVANS
DAVID GERBER
GREGORY C. GLYNN
RICHARD GOODYEAR
H. JEFF GREENFIEL.
CHARLES H. HERZ
DAVD HESS

\author{
BETSY LEVIN \\ Topics Editor \\ Raymond C. Clevenger, III \\ MARK A. WALKER \\ Article \& Book \\ Review Editors
}

Dennis E. Curtis

Managing Editor

B. BOYD HIGHT, JR. ALAN C. HOOKER

C. STEPHEN HOWARD WILLIAM IVERSON GeORGE A. Johnson GeORGE L. JUROW LINDSEY C. Y. KIANG Howard A. KNIGHT Simion Lazarus, III RONAID F. LIPP PhiLIP LochNer RICHARd Markovits Victor MARRERO ALAN R. McFarLand, JR, ROBERT F, WALRPR Frederick B. McLANe Silas Wasserstrom Theodore Miller JefFrey WoOd MichaEl MUKasey HenRY WOOdWaRd John E. Nathan Mattiew Zwerling
Hamilton Osborne, JR. Donalioson C. Pullsdury Chiarles A. Pulaski, Jr. LEONARD M. ROSS ERIC SCHNAPPER Philip Gordon Schrag John Schulz ALAN D. SISITSKY Allan G. Sperling LEONARD P. STRICKMAN RODERT TANNEN David F. Tillótson Michaed S. Wald ROBERT F. WALKER
Arthur D. Hellman
M. Olive Butterfiend
Business Manager
Business Secretary

\section{CONTRIBUTORS TO THIS ISSUE}

Christoph SAsSE. Referendar 1953, Dr. iur. 1957, University of Marburg; Assessor 1960, Wiesbaden.

Gerald C. MacCallum, JR. B.A. 1950, M.A. 1954, Ph.D. 1961, University of California, Berkeley.

Gerald T. Dunne, B.S. 1919, Georgetown University; LL.B. 1948, St. Louis University. 